\title{
Fuzzy Logic Based Energy Controlling Strategy for Isolated Wind-PV Hybrid System
}

\author{
Saravanan S., Ramji Tiwari, Pandiyan P., Kumar K., Ramesh Babu N.
}

Keywords: Energy management, Fuzzy logic approach, maximum power point tracking, photovoltaic system.

\section{INTRODUCTION}

The continuous reduction of finite resources and increase in population led the use of alternative energy instead of coal based production. The renewable energy sources (RES) are the hopeful solutions for clean green energy. The enhanced efficiency and low pollution makes RES as better option to supply of power to the consumers [1]. Solar energy and wind energy are more utilized because it is readily everywhere. The revolutionary advancement in power converters [2],[3] made the system very effective in tracking of maximum power and hence improves the performance of the total system. Permanent Magnet Synchronous Generator (PMSG) based wind turbine is mostly chosen due for its ease, reliability and no requirement of gear box [4].

MPPT control algorithms are generally integrated into system so as to capture the maximum available power from

Revised Manuscript Received on February 05, 2020.

* Correspondence Author

Saravanan S., Department of Electrical and Electronics Engineering, Sri Krishna College of Technology, Coimbatore, Tamilnadu, India. E-mail: saravanan.s@skct.edu.in

Ramji Tiwari, Department of Electrical and Electronics Engineering, Bharat Institute of Engineering and Technology, Hyderabad, India. E-mail: tiwariramjis@gmail.com

Pandiyan P.*, Department of Electrical and Electronics Engineering, Sri Krishna College of Technology, Coimbatore, Tamilnadu, India. E-mail: pandiyan.p@skct.edu.in

Kumar K., Department of Electrical and Electronics Engineering, SV College of Engineering, Tirupathi, India. E-mail: kumar3kk@gmail.com

Ramesh Babu N., Department of Electrical and Electronics Engineering, M. Kumaraswamy College of Engineering, Karur, Tamilnadu, India. E-mail: nrameshme@gmail.com

(C) The Authors. Published by Blue Eyes Intelligence Engineering and Sciences Publication (BEIESP). This is an open access article under the CC BY-NC-ND license (http://creativecommons.org/licenses/by-nc-nd/4.0/)

\begin{abstract}
The paper proposes a fuzzy logic based energy management strategy for isolated hybrid $P V$-Wind system. This $P V$-Wind system comprises of $500 \mathrm{~W}$ photovoltaic (PV) systems and $600 \mathrm{~W}$ permanent magnet based alternator for conversion of wind energy. A step down converter is connected to the system in order to charge the $48 \mathrm{~V}$ battery electric storage system (BESS). The load of $1 \mathrm{~kW}$ system is supplied with the $1.1 \mathrm{~kW}$ hybrid systems. The renewable energy sources are intermittent in nature and hence BESS system is used to support the load when there is shortage of energy generated. To optimize the output voltage of the fuzzy logic approach based maximum power point tracking (MPPT) method is employed which is also utilized for the energy management strategy. The proposed topology is modeled and simulated using mathworks tool MATLAB/Simulink and its performance is evaluated.
\end{abstract}

varying wind speed and solar irradiations by changing the firing angle of the converter. Various MPPT techniques have been employed in the literature for Wind Energy Conversion System (WECS) and Solar PV system such as Hill Climbing technique (HC) , Incremental and Conductance technique (INC), Perturb and Observe (P\&O) technique, Fuzzy Logic approach (FL) and many Evolutionary Algorithms. Perturb and Observe technique is popularly used MPPT technique due to its simplicity and effectiveness. But the rapid variation in wind speed and the solar irradiations causes the $P \& O$ to track the optimal point of the system and thus the MPPT fails the primary objective. Thus Fuzzy logic Controller (FLC) is used in this system because it tracks the maximum power for rapid variations because they have pre-defined data for the system [5], [6].

To integrate the proposed system to the DC Microgrid, a buck converter based DC to DC converter is employed in this research. The alternating current (AC) obtained from WECS is converted into direct current (DC), a diode bridge rectifier is implemented [7]-[9]. The MPPT control strategy tracks the variation in wind speed and solar irradiations for generation of corresponding firing pulse [10]-[15].

The proposed topology is integrated with the storage system so as to provide power to load when the renewable energy is not sufficient. To enhance the performance of the renewable based hybrid system, an efficient fuzzy logic controller is used in this paper. The proposed work also analyses the energy loss associated with the DC/DC converter.

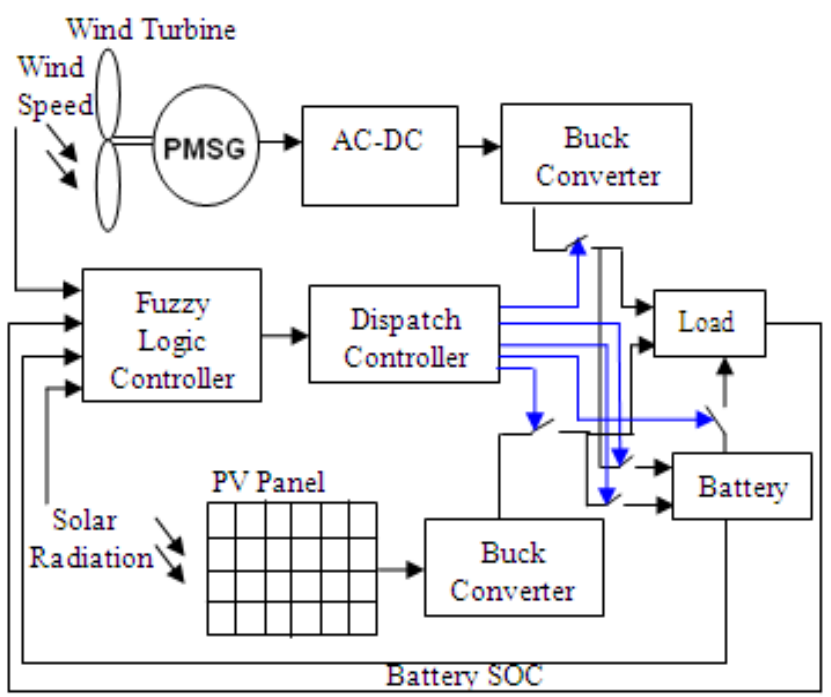

Fig. 1. Proposed topology for hybrid PV and wind. 


\section{MODELLING OF HYBRID WIND-PV SYSTEM}

The parameter modeling deals with WECS, PMSG, PV system and converters that constitute the whole hybrid system are explained in this section. A hybrid PV-WECS based renewable energy system with individually dedicated buck converters is considered for modelling as shown in Fig. 1 .

\section{A. Design of PV system}

The power output obtained from PV relies on the availability of irradiance and temperature. A single diode based PV model is implemented in this work as shown in Fig. 2. The PV system used for consideration is $500 \mathrm{w}$ of BP Solar SX3190 PV module in this proposed work. The modeling of $\mathrm{PV}$ system is derived from $\mathrm{I}_{\mathrm{PV}}-\mathrm{V}_{\mathrm{PV}}$ characteristics of $\mathrm{PV}$ panel are follows.

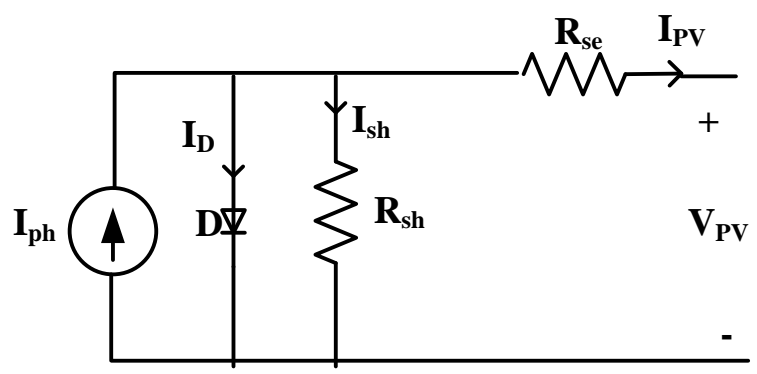

Fig. 2. Equivalent circuit of Solar PV system

$$
I_{p v}=I_{p h}-I_{p v r s c}\left(e^{\frac{q\left(V_{p v}+I_{p v} R_{s}\right)}{\eta K T}}-1\right)-\frac{V_{p v}+I_{p v} R_{s e}}{R_{s h}}
$$

where, $R_{\text {sh }}$ : Shunt resistance of single diode model $(\Omega), V_{\text {oc }}$ : Open circuit voltage $(\mathrm{V}), \mathrm{I}_{\mathrm{sc}}$ : Short circuit current $(\mathrm{A}), \mathrm{R}_{\mathrm{se}}$ : Series resistance of single diode model $(\Omega), \eta$ : Ideality factor, T: Ambient temperature (K), IPV: PV panel output

\section{B. Design of WECS}

Wind speed $\left(\mathrm{V}_{\mathrm{w}}\right)$ which is the driving factor for wind turbine (WT) along with rotor speed and pitch angle and it gives mechanical output power . The total mechanical output power $\left(\mathrm{P}_{\mathrm{m}}\right)$ produced by $\mathrm{WT}$ is proportional to the wind velocity and estimated through Eq. (2).

$$
P_{m}=\frac{1}{2} \rho A C_{p}(\lambda, \beta) V_{v}^{3}
$$

Where, A refers to Swept area of wind blade, $\lambda$ is the Tip speed ratio, $\beta$ is the Blade pitch angle (degree), $\rho$ denotes the Air density $\left(\mathrm{Kg} / \mathrm{m}^{3}\right)$ and $\mathrm{C}_{\mathrm{p}}$ refers to Rotor power coefficient. A 600W PMSG based WECS system is used for the proposed control strategy topology. The wind power produced by the WECS is purely depends on the wind velocity at the given time.

\section{Design of DC/DC Buck Converter}

The buck converter is used as a DC to DC converter in this paper. The output voltage of the Buck converter is controlled using duty cycle. The converter proposed in this study works with two varieties of conduction modes such as continuous and discontinuous mode. The relationship between input and output voltage of the converter is represented in the Eq.3 current (A).

$$
V_{\text {out }}=V_{\text {in }} * D
$$

where $V_{\text {out }}$ is the average DC output Voltage $V_{\text {in }}$ is the input DC voltage and $D$ denotes the duty cycle of switch employed in the buck converter.

Table I - Parameters of buck converter

\begin{tabular}{|l|l|}
\hline Inductor (L) & $3.65 \mathrm{mH}$ \\
\hline Capacitor (C) & $3 \mathrm{mF}$ \\
\hline Load (R) & $150 \Omega$ \\
\hline
\end{tabular}

In Table I. gives the value of $\mathrm{L}$ and $\mathrm{C}$ for simulation study is determined.

\section{Design of Battery management system}

The lead acid battery rated at $48 \mathrm{~V}$ is considered for the study. The battery management system (BMS) is provided with the overcharging and deep discharging protective devices. Thus providing an efficient control system during surplus and depict of power. BMS is a key component of energy management system to provide a constant supply to load during low power generation time. A $48 \mathrm{~V}$ lead acid battery is considered for the study. The electrical representation of lead acid battery is as follows,

$$
V_{s}=E_{b a t}+I_{b a t} * R_{b a t}
$$

Where, $V_{s}$ is represented as internal terminal voltage, $E_{b a t}, I_{b a t}$ and $R_{b a t}$ is the battery voltage, current and resistance respectively.

\section{PROPOSED ENERGY MANAGEMENT SYSTEM}

The power generation of renewable energy generation is purely depends upon the climatic condition. The continuous power supply to load is also a major concern which is purely depending on the battery conditions. The consideration of the energy management system to prove the effectiveness of the proposed system is shown in Table II. The control strategy for controlling the battery system is considered by analysing the rated battery voltage of $48 \mathrm{~V}$ and supplying voltage between $\pm 5 \mathrm{~V}$ (53 V to $43 \mathrm{~V})$.

The battery regulation employed for hybrid system is considered in this work is depicted in Fig. 3. The regulation consists of two hysteresis band. The reference power remains constant If voltage falls between the hysteresis bands and stops charging the battery if voltage is beyond $\mathbf{V}_{\mathbf{d c} \_ \text {high, }}$ inside the area "H".

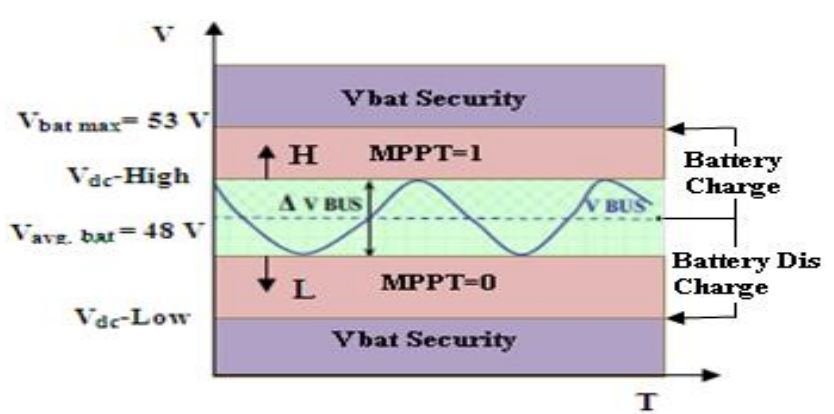

Fig. 3. Regulation of proposed energy management system 
TABLE II -Parameter consideration of Fuzzy logic system

\begin{tabular}{|c|c|c|c|}
\hline \multicolumn{4}{|c|}{$\begin{array}{l}\text { Fuzzy input (Solar Irradiation, Wind Speed and } \\
\text { Battery) }\end{array}$} \\
\hline Time & $\begin{array}{l}\text { Solar } \\
\text { irradiance } \\
\mathrm{w} / \mathrm{m}^{2}\end{array}$ & $\begin{array}{l}\text { Wind } \\
\text { speed } \mathrm{m} / \mathrm{s}\end{array}$ & Battery Voltage \\
\hline $\mathrm{T} 1$ & Off & Off & 48 Vbat_nom \\
\hline $\mathrm{T} 2$ & Off & 14 & 45 Vbat_min \\
\hline T3 & 1000 & 10 & 45 Vbat_min \\
\hline $\mathrm{T} 4$ & 1000 & Off & 53 Vbat_max \\
\hline T5 & 1000 & 14 & $\begin{array}{l}43 \text { Vbat_low } \\
\text { (security mode) }\end{array}$ \\
\hline
\end{tabular}

\section{A. strategy}

The shortcomings encounter in the convention control strategy method Fuzzy Logic approach based controller (FLC) is utilized in this article. FLC system converges very fast and better controllability in non linearity. FLC consists of three steps such as Fuzzification, Rule based lookup table and Defuzzification as shown in Fig.4. The knowledge of the system is required to frame the rule for fuzzy system. The current and voltage are the inputs to the FLC. The firing pulse required for DC-DC buck converter is obtained from the FLC by employing the fuzzy rules.

Table. III, depicts the fuzzy rules used in the present work. The rules are framed in five levels such as Negative High (NH), Negative Low (NL), Zero(ZE), Positive Low (PL) and Positive High $(\mathrm{PH})$. The centroid approach is utilized for defuzzification process.

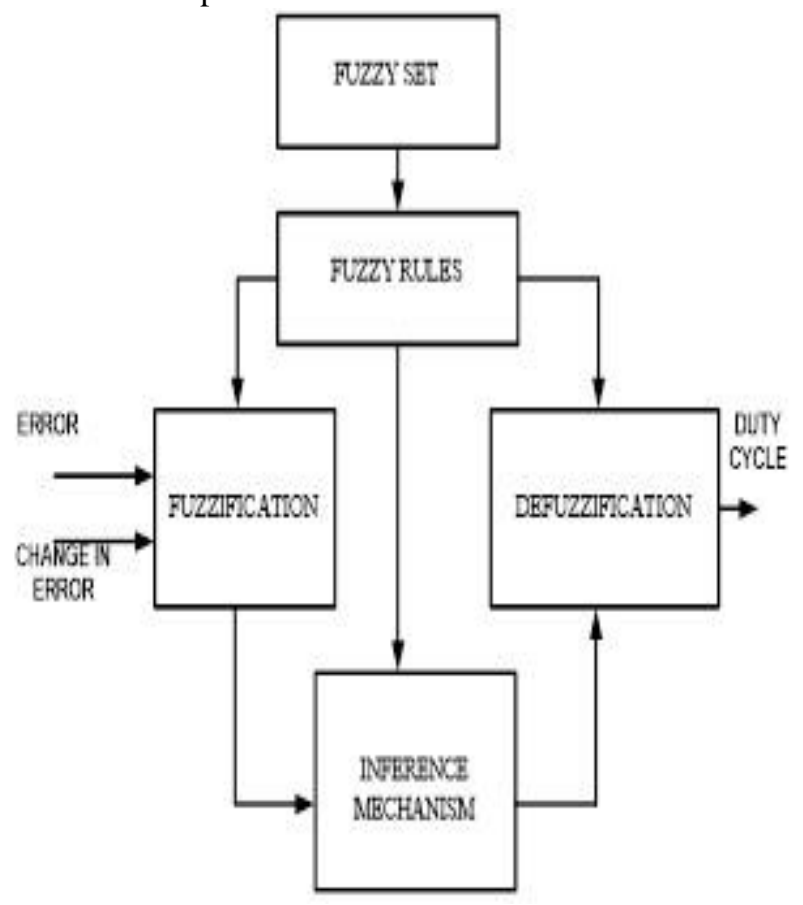

Fig. 4. Block diagram of FLC

Table III- FLC Set of rules

\begin{tabular}{|l|l|l|l|l|l|}
\hline E/CE & NH & NL & ZE & PL & PH \\
\hline NH & ZE & PH & ZE & NH & NL \\
\hline NL & PS & ZE & ZE & NH & NL \\
\hline ZE & ZE & ZE & ZE & ZE & ZE \\
\hline PL & PL & PH & ZE & ZE & NS \\
\hline PH & PL & PH & ZE & NH & ZE \\
\hline
\end{tabular}

The major advantage of FLC system is its ability to track the sudden change in parameters of PV and WECS. The FLC strategy tracks the change in output parameters of the system and an errror signal is generated. The error signal is changed to fuzzy sets by using Mamdani method in fuzzification process. The fuzzy sets are processed using the rules and inference system. Once the fuzzy values is processes, the fuzzy linguistic variable is converter into data set using defuzification process. Thus the firing pulse is obtained using the FLC process for different input variables.

\section{RESULTS}

The performance of hybrid PV-WECS system employing DC-DC buck converter integrated with FLC is evaluated using simulation tool MATLAB/ Simulink in this study. The efficiency of the proposed system is validated for different climatic condition is tested as stated earlier. Fig, 5 shows the output DC voltage obtained from the hybrid system. The aim of this proposed hybrid energy harvesting system is to produce constant DC voltage supplied to the load. The output obtained by proposed control strategy by implementing fuzzy logic based control system is illustrated in Fig. 6. Proposed control strategy utilises the battery when the power generation from the renewable energy generation is low. The battery voltage is also showed in the Fig. 6 . The proposed control strategy also maintains the constant voltage in order to supply the constant supply to load.

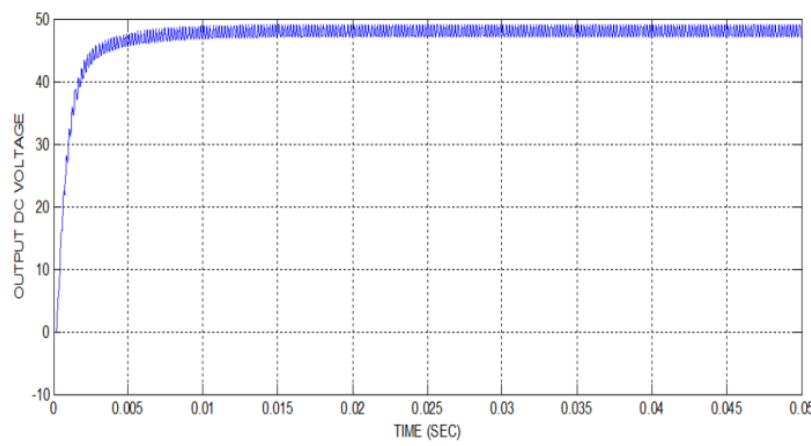

Fig. 5. DC bus voltage

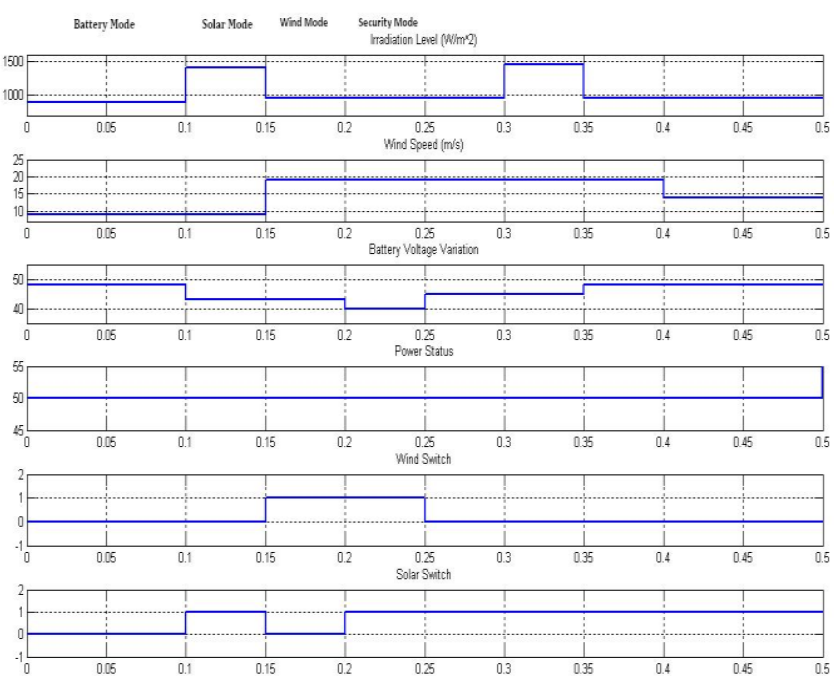

Fig 6. Simulation of overall power management of fuzzy based hybrid Wind-Solar system.

Published By: 


\section{CONCLUSION}

The fuzzy logic based energy management system is modelled and investigated using MATLAB/Simulink. The proposed topology consists of hybrid system of PV and wind energy conversion system. Battery management system is also utilised in the proposed system in order to support the load during the low power generation condition. The system is incorporated with the buck converter to support the load voltage. The proposed system is considered for the remote location application where the energy management plays a vital role. The wind, solar and battery voltage condition is considered as the input voltage along with reference power which is considered with load demand. The output extracted from FLC is better and efficient than that of conventional approach by means of stability constraint, tracking control and fluctuations. Hence, it is concluded that the FLC based energy management system is the best option for standalone hybrid renewable system for remote location system.

\section{REFERENCES}

1. Tiwari R., Babu, N.R.,: Recent developments of control strategies for wind energy conversion system. Renew. Sustain. Energy Rev., 66 (2016) 268-285.

2. Xu D., Zhou B., Chan KW., Li C.B., Wu Q.: Distributed Multi-Energy Coordination of Multi-Microgrids with Biogas-Solar-Wind Renewables. IEEE Trans. Ind. Info. 15(6) (2019) 3254-3266.

3. Kumar K., Babu N.R.,. Prabhu K.R.: Design and Analysis of RBFN-Based Single MPPT Controller for Hybrid Solar and Wind Energy System. IEEE Access 5 (2017) 15308-15317.

4. Tiwari R., Babu, N.R.,: Comparative Analysis of Pitch Angle Controller Strategies for PMSG Based Wind Energy Conversion System. Int. J. Intel. Sys. and App. 5 (2017) 62-73.

5. Sudha R., Reddy D., Saravanan S., Babu C.B.: Comparative Analysis of RBFN and Fuzzy-SVPWM Controller Based Boost Type Vienna Rectifier for 1kW Wind Energy Conversion System. J. Green Eng., 8(2) (2018) 177-200.

6. Himri Y., Stambouli AB., Draoui B., Himri S.: Techno economical study of hybrid power system for a remote village in Algeria. Energy, 33 (2008) 1128-1136.

7. Kumar A., Kandpal TC.: Renewable energy technologies for irrigation water pumping in India: a preliminary attempt towards potential estimation. Energy, 32 (2007) 861-870.

8. Jain S., Agarwal V.: An Integrated Hybrid Power Supply for Distributed Generation Applications Fed by Non-conventional Energy Sources. IEEE Trans. on Energy Convers., 23 (2008) 622-631.

9. Reddy, K.J., Sudhakar, N., Saravanan, S. and Babu, B.C., 2018. High Step-Up Boost Converter with Neural Network Based MPPT Controller for a PEMFC Power Source Used in Vehicular Applications. International Journal of Emerging Electric Power Systems, 19(5).

10. Rajangam, K., S.V. Sreekanth Reddy, T.V. Santhosh ,Gopika Vinod, Shiju Varghes, Jay Shah., "Reliability Prediction of Seismic Switch for Early Detection of Earthquake at NPP Site", International Journal of System Assurance Engineering and Management- Springer. Vol.7, No.3, pp. 325-331, 2016

11. Kumar P.S., Gayathri R., Senthamarai C., Priyadharshini M., Fernando P.S.A., Srinath R., Kumar V.V. Kinetics, mechanism, isotherm and thermodynamic analysis of adsorption of cadmium ions by surface-modified Strychnos potatorum seeds Korean Journal of Chemical Engineering .vol 29 issue 12 pp 1752- 1760,2012

12. Bhuvaneswari K., Rauf H.A., Edgelet based human detection and tracking by combined segmentation and soft decision 2009 International Conference on Control Automation, Communication and Energy Conservation, 5204487 INCACEC 2009

13. Jameer Basha A., Palanisamy V., Purusothaman T. Efficient multimodal biometric authentication using fast fingerprint verification and enhanced iris features, Journal of Computer Science Vol 7 issue 5 pp 698706,2011

14. Punithavathani D.S., Sankaranarayanan K. IPv4/IPv6 transition mechanisms, European Journal of Scientific Research vol 34 ,issue 1,PP 110-124,2009
15. Sreeja N.K., Sankar A. Pattern matching based classification using Ant Colony Optimization based feature selection, Applied Soft Computing Journal VOL 31 issue 2818 PP 91-102,2015

\section{AUTHORS PROFILE}

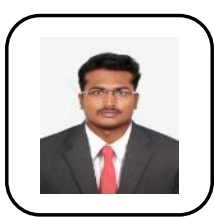

Saravanan S., received the B.E. degree in Electrical and Electronics Engineering in 2012 from Karpagam College of Engineering, Coimbatore, India. and M.E. degree in Power Electronics and Drives in 2014 respectively from Sri Krishna College of Engineering and Technology, Coimbatore, India. Also, he obtained his Ph.D. degree in 2017 from VIT University, Vellore, India. Currently, he is an Assistant Professor of Department of Electrical and Electronics Engineering, Sri Krishna College of Technology, Coimbatore, India. His areas of interest include Power Electronics and Applications of power electronics in renewable energy systems.

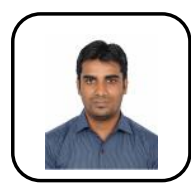

Ramji Tiwari, is an Assistant Professor and Bharat Institute of Engineering and Technology, Hyderabad. He completed his B.E. degree in Electrical and Electronics Engineering in the year 2012 from Kathir College of Engineering, Coimbatore and Masters Degree in Power Electronics and Drives from Sri Krishna College of Engineering and Technology, Coimbatore in the Year 2014. He completed his Ph.D degree from VIT University in the year 2019. He has authored and coauthored more than 20 publications in reputed International Journal and Conferences. His research area includes Renewable energy, optimal control of wind energy conversion system, solar energy, Power Electronics, and Application of Soft Computing techniques in Electrical Engineering.

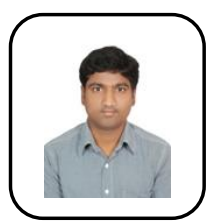

Pandiyan P., was born in Aruppukottai, Tamil Nadu, India, in 1985. He received the Bachelor's Degree in Electrical and Electronics Engineering from Anna University, Chennai, India, in 2006; Master's Degree in the Department of Electronics and Communication Engineering from Sathyabama University, Chennai, India, in 2010 and the PhD Degree in Instrumentation and Control Engineering from the National Institute of Technology, Tiruchirappalli, India, in 2018. He is currently working as an Assistant Professor in Electrical and Electronics Engineering Department at Sri Krishna College of Technology, Coimbatore. His research interests include design and simulation of MEMS based logic devices and Energy harvesting.

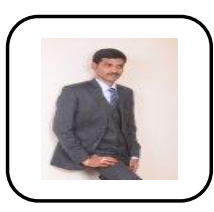

Kumar K., received the B.Tech. degree in electrical and electronics engineering and the M.Tech. degree in power electronics and electrical drives from the SV College of Engineering, JNTUA ,in 2011 and 2013, respectively. He is currently working as an Assistant professor, SV College of Engineering, Tirupathi. Research work focused in the field ofpower electronic applications in the renewable energy system.

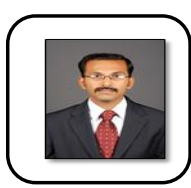

Ramesh Babu N., received his B.E. degree in Electrica and Electronics Engineering in Bharathiar University, India, and received his M.E. degree in Applied Electronics from Anna University, India. Also, he obtained his Ph.D. degree from VIT University, India. Currently, he is a Principal of M. Kumarasamy College of Engineering, Karur. He is Associate Editor in IEEE Access. His current research includes Wind Speed Forecast, Optimal Control of Wind Energy Conversion System, Solar Energy and Soft Computing techniques applied to Electrical Engineering. 